\title{
Reading Textural Functions, Instrumental Techniques, and Space Through Partition Complexes
}

\author{
*Pauxy Gentil-Nunes \\ Federal University of Rio de Janeiro (UFRJ) \\ pauxygnunes@musica.ufrj.br \\ Orcid: 0000-0003-1548-7694 \\ DOI: $10.46926 /$ musmat.2020v4n2.80-97
}

\begin{abstract}
Partitional complexes are sets of discrete textural configurations (called shortly of partitions in Partition Analysis) that successfully interact to construct a global textural structure. This textural mode is called the Textural Proposal of a piece, where referential partitions (those that represent the main features of textural configurations in the excerpt) stand out. This conceptual environment, developed in musical texture formalization through observation and musical repertoire analysis, is now applied to musical practice. In the present work, we highlight three of these situations. The first one deals with the creative flow (compositional process) and its relation with textural planning. The second observes how these same textural functions condition the body's physical coupling to the instrument (fingers, hands, pedals, instrumentation). Finally, just as an introduction, we envisage some spatial relations, involving instrument distribution on stage, emphasizing historical concert music.
\end{abstract}

Keywords: Texture. Partitional Analysis. Textural Design. Performative Partitioning. Partitional Complex.

\section{INTRODUCTION}

$\mathrm{M}$ any authors have discussed musical texture as a subject associated with hierarchical levels of the musical discourse, usually as a surface feature ([7], [18], [8]). The tension between the musical structure (commonly correlated to harmonic and formal units observed in large time spans) and the musical surface is one of the interests raised by some post-tonal theorists (for instance, [2]).

This question guides the research project called Surface and Structure in Applications of Partitional Analysis (2018) [16], developed in the Graduate Program in Music of the Federal University of Rio

*This work brings the content of a conference in the round table "Theories of the Texture" in the III Congress of the Brazilian Association of Musical Theory and Analysis (TeMA) and the IV International Congress on Music and Mathematics, held in 2019 in the city of Rio de Janeiro.

Received: December 26th, 2020

Approved: December 28th, 2020 
de Janeiro. It came as a natural arrival of former projects, since the year 2003, all revolving around the formalization of texture through the application of the Theory of Integer Partitions, leading to a field called Partitional Analysis (henceforward, PA - [10], [13], [15]).

In the earlier years (2003-2009), PA gradually consolidates by developing proper musical analysis and composition tools. Since 2009, researchers have made some effort in applying these concepts to practical musical situations, internal and external to the theoretical realm, leading to new approaches and the expansion of the limits of the theory.

The more recent lines of research inside PA concentrate on three main fields:

1. Textural Design - the proposal by Daniel Moreira brings together the expanded application in the compositional process of PA tools combined with Compositional Design concepts by Robert Morris [29], as well as original tools. ([21], [22]).

2. Performative partitioning - formalizes the relation between textural configurations and the coupling of the body (fingers, hands, arms) and musical instruments. Bernardo Ramos ([34], [33], [35]), Pedro Miguel de Moraes [20] and the present author [14] work on this approach.

3. Spacial partitioning - as an introduction, we make in the present paper some preliminary observations about this application, foreseen in earlier publications ([12]).

Next, we will make a brief elaboration of each one of these applications, in order to draw some lines for the near future of the research.

\section{Textural Design}

Daniel Moreira has achieved some remarkable advances in the expansion of PA concepts in successive publications, using the Countour Theory ([9], [30], [19]) to enable the partitions a possibility of a linear organization ([27], [26], [25], [24], [23]). In 2019, Daniel defended his doctoral dissertation, with Robert Morris' supervision, where he proposes a combination of PA concepts with Morris' Compositional Design principles to arrive at the Textural Design theory, where he also brings original ideas and tools. ${ }^{1}$

One of the most striking features of Moreira's work is the expansion of the textural space in two opposite directions.

First, taking the partition level as a reference, Moreira proposes a generalization of partitional structure through a quality evaluation, reading the parts just as lines or blocks. This categorization was made earlier by Ramos [33], but Moreira deepened his reading, proposing a Hasse diagram for the textural class space - the tc-space lattice (Figure 1). In addition to organizing the inclusion relations, Moreira qualitatively evaluated the parsimonious operators between the elements (shifting, linear layering and block layering). Moreover, he provided numerous analytical examples and original related concepts, such as monopart, polypart, isopart, and heteropart.

As a second step, Moreira proposes instantiations of partitions in the musical surface direction through ordered partitions and thread-words. Ordered partitions are known in mathematics as compositions and consider each permutation of the parts inside the partition as a distinct element. On the other side, thread-words allow the evaluation of parts constituted by non-neighbor components (or threads), e.g., textural configurations with interpolated parts. The comprehensive set of textural spaces - Textural class space, Unordered partitions space and Partition layout space (Figure 2) - comprises a global taxonomy of textural codes.

\footnotetext{
${ }^{1}$ As Moreira has published a paper about Textural Design in the present journal ([21]), we highly recommend the reading, as he provides a much more detailed discussion for the subjects briefly explained in this subsection. His doctoral thesis is also available ([22])
} 


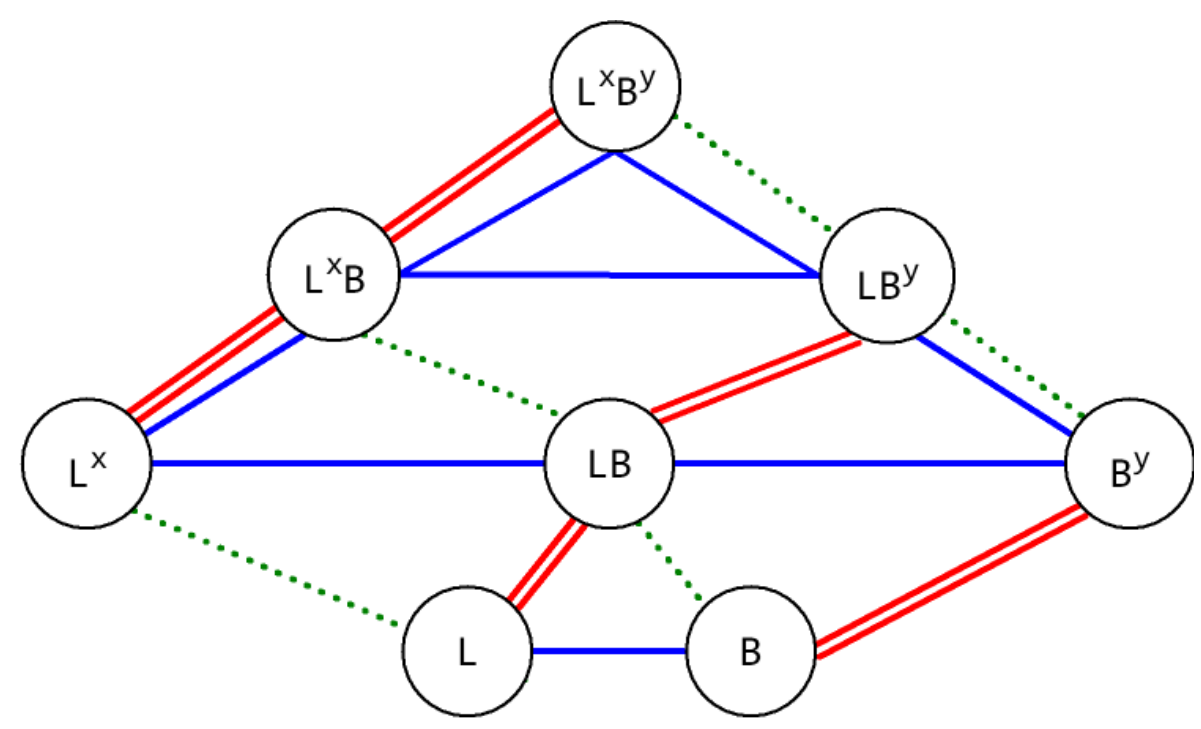

Shifiting (F)

..... Linear Layering $\left(\mathrm{Y}_{\mathrm{L}}\right)$

Block Layering $\left(\mathrm{Y}_{\mathrm{B}}\right)$

Figure 1: Textural class lattice: all textural classes connected by layering (Y) and shifting (F) operations ([21], p. 26).

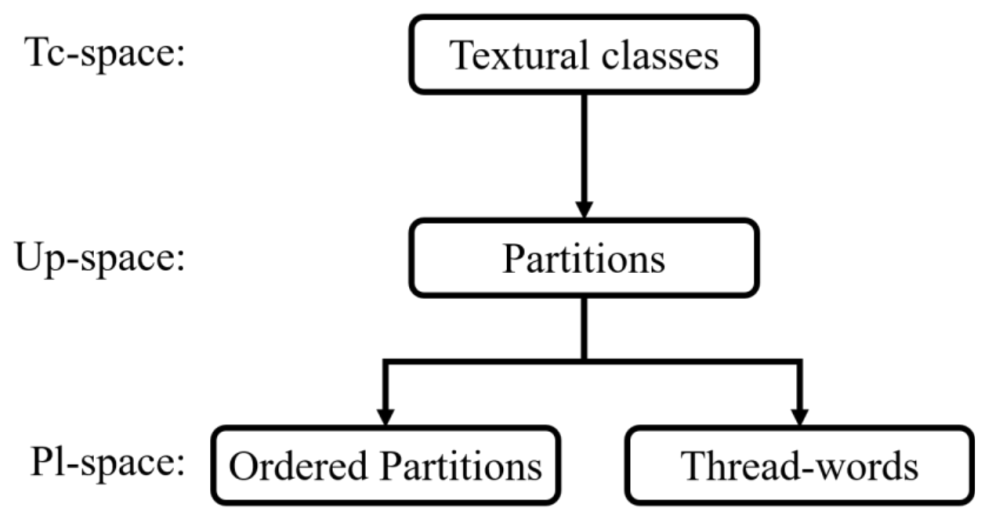

Figure 2: Inclusion relations among textural codes within textural spaces ([21], p. 33). 


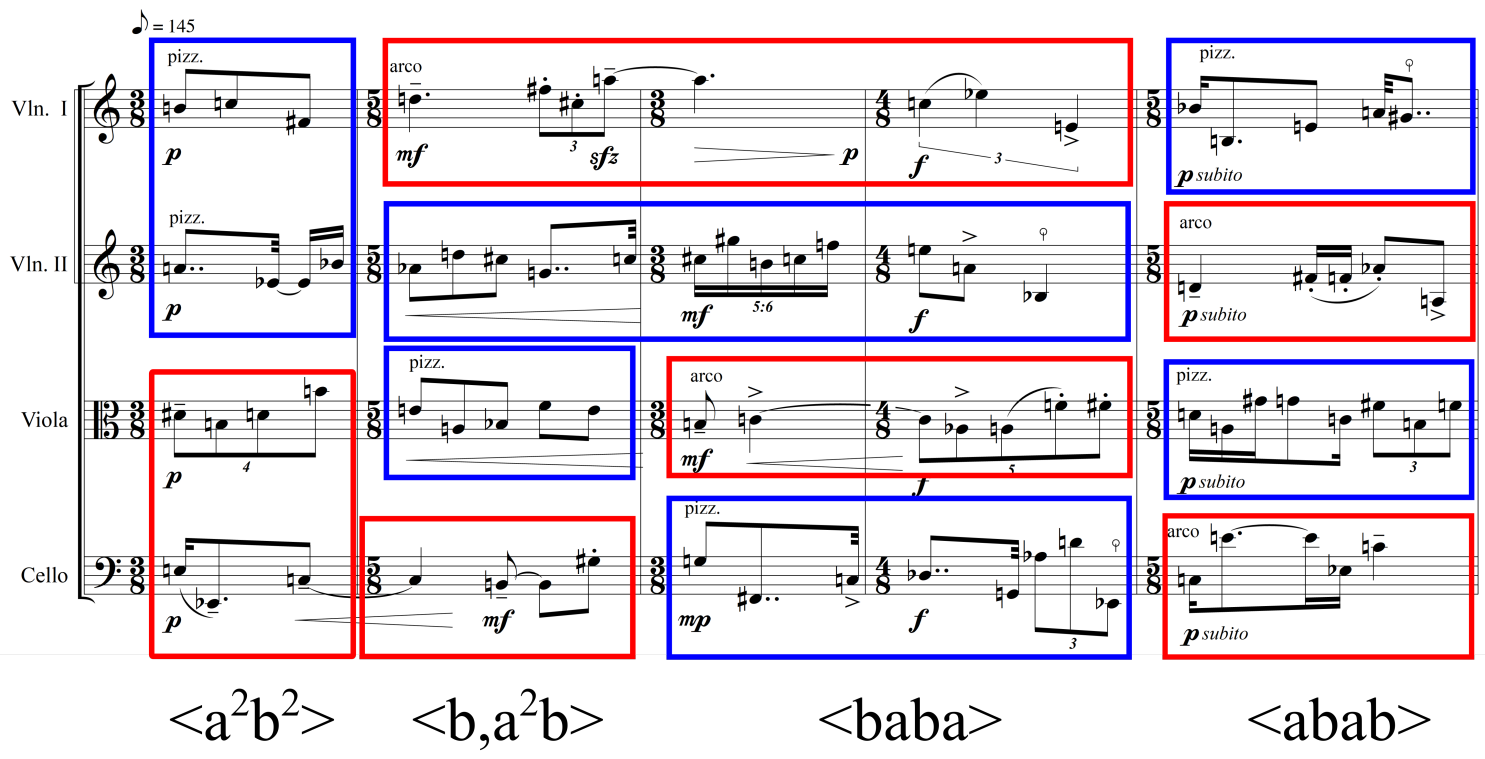

- Block $\{2\}$ - Pizzicato | pc-set 3-5[016]

- Block $\{2\}$ - Arco | pc-set 3-3[014]

Figure 3: Thread-words producing different organizations of threads within partition $\left[2^{2}\right]$ (adapted from [21], $p .32$ ).

One crucial point is that Moreira provides a series of musical examples (original and from repertoire) that use criteria that meet the composer's direct interest and point to the surface as well. For example, the articulation or timbre of the instruments (Figure 3).

In order to attend the specific needs of the compositional process, Moreira highlights five modes of textural realization, each representing a recurring procedure regarding the construction of musical textures: a) Standard Mode; b) Partitional Complex; c) Evolving mode; d) Colorization; e) Montage ([21], p. 153). These concepts are actual examples of a contribution from applying theory to musical practice.

\section{Performative Partitioning}

The centrifugal tendency of textural analysis led the analyst sight from inside to outside the score, where the contact between the body and the instrument causes the gestures that constitute the musical surface. Bernardo Ramos proposes this approach in his analysis of the 20 Estudios Sencillos for guitar by Leo Brouwer [33]. The main question was about the construction of the Etudes' progressiveness in terms of textural writing for the instrument. For instance, the textural configurations could become gradually more complex, or its number and degree of changes could just level up.

The conclusion is that the accrual grows towards more advanced technical demands with no replacement but accumulation. Still, the prevalence of some textural configurations follow a specific pattern (Table 1$)$.

The partitions $(1),\left(1^{2}\right),(1.2),(3)$ and $\left(1^{3}\right)$ are the most used in the series. Some common features between them can explain their prominence. They easily demand the three main fingers of the right hand - the thumb, index, and middle (noted in the score as $p, i$, and $m$, respectively). 
Table 1: Distribution of partitions in Leo Brouwer's 20 Estudios Sencillos ([3]) in order of occurrence in the series ([36], p. 21). The last line shows the number of Etudes where each partition occurs.

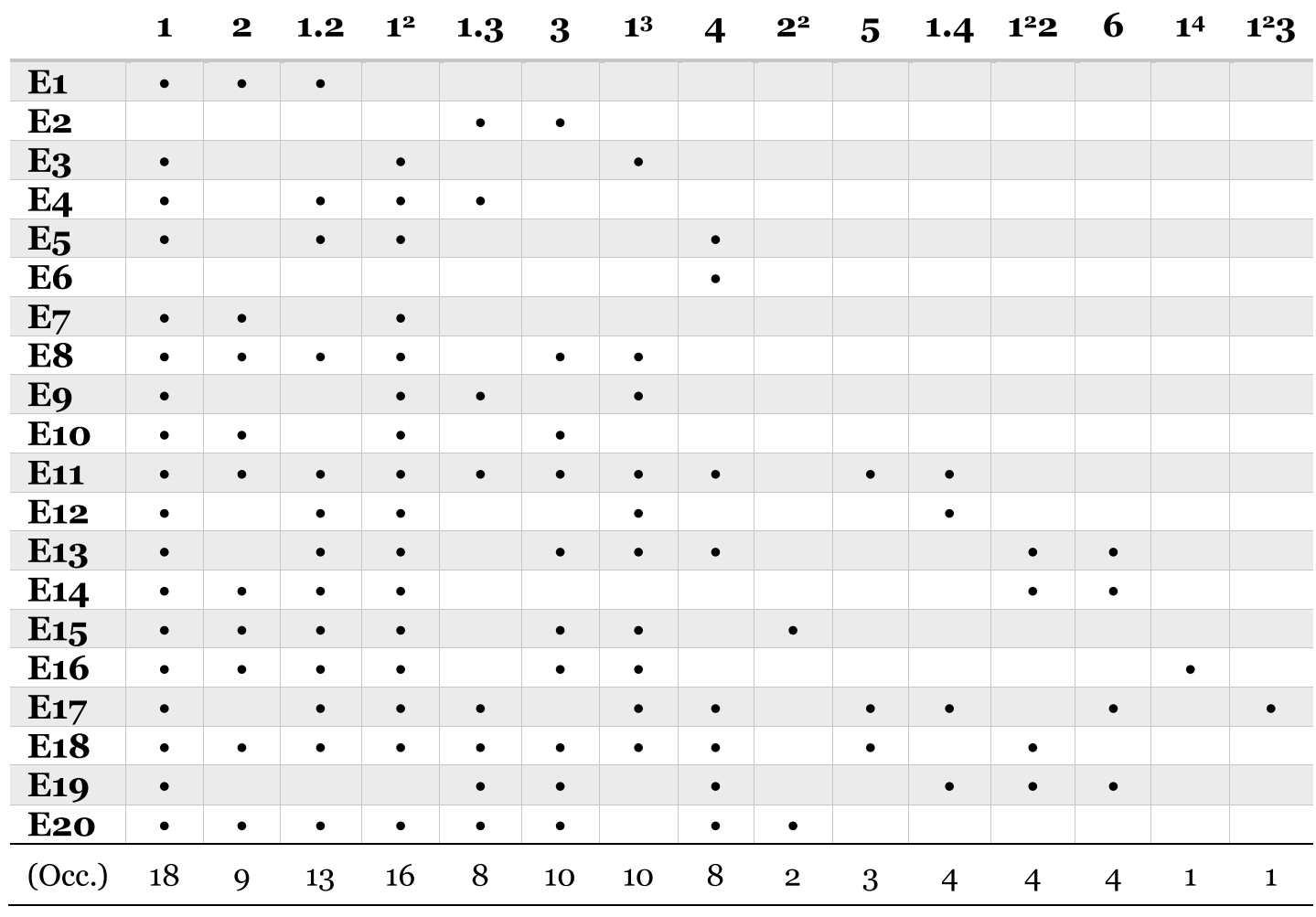

Almost all occurrences involve these fingers. The thumb is responsible for nearly every unitary part, notably when it combines with a block - in partition (1.2), for instance.

What emerges from the analytical conclusions is that the observations returned to the human hand's shape with its opposable thumb, bringing the ergonomy of the human body into the scene and the force of instrumentation in determining the textural discourse.

The first Etude shows this correlation with clarity. The alternation between the parts (1) - the thumb playing the melody - and (2) - the combination of index and middle finger performing a steady harmonic dyad as an accompaniment - is dominant throughout the piece (Figure 4). Eventually, each part articulates separately, and there could yet be a simultaneous attack, merging the parts. The set of all these combinations - in this case, partitions (1), (2), and (1.2) - expresses a type of textural mode that can define some specific instrumental writing. There is, too, one or more partitions that prevails over the others, establishing a hierarchic structure.

The addition of the technical procedures for performing the textural mode to the partition constitutes the Textural Proposal (TP) of a piece or excerpt. As each instrument always has specific technical demands derived from its physical and historical domain, their TPs tend to be exclusive.

The enumeration and assessments of TPs, based on the instrument's technique and practice, is now one of the goals of this area, called then as Performative Partitioning.

For instance, Ramos proposes the evaluation of all possible GTPs (Guitar Textural Proposals) 
a)

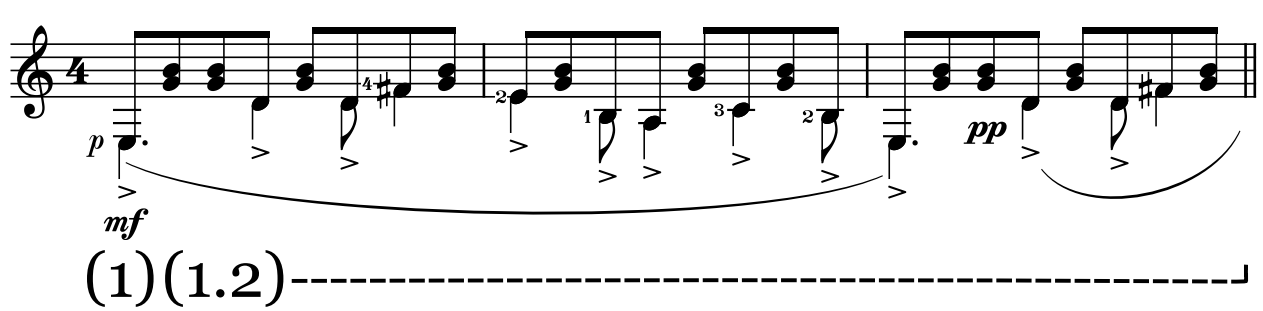

b)

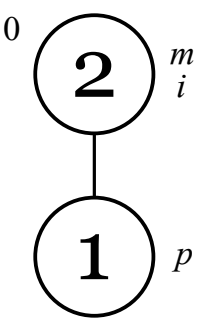

Figure 4: a) Etude No. 1, excerpt with partitions (1) and (1.2) ([3], mm. 1-2). b) Diagram of its GTP. The letters in italics indicate the fingers of the right hand that articulate the parts nearby. The numeral 0 on the upper left side of part (2) indicates that the part is performed using notes located on open strings ([35], p. 11).

associated with partition (1.2). The reflection begins with the uses of this structure in Brouwer's Etudes. The Cuban composer resort to basic techniques, like open strings, inversion of registers, and left-hand slurs. But even in this restricted universe, with a single partition and elementary procedures, some combinations were not used. Ramos enumerates the missing ones and shows how they can form a net of parsimonious relations (Figure 5).

Pedro Miguel de Moraes follows the same path, applying PA's concepts to the performative partitioning in the piano writing. Unlike the guitar, where the left hand selects the pitches and the right produces the sound, both hands simultaneously perform two functions on the piano. From this point, the research splits into three large branches, following the work of Claude Cadoz [4]: assessing selection gestures (comprising hand shapes), excitation gestures (where are directly applied the partitions and partition complexes) and structural modification gestures (in the piano, the pedal, changing the textural modes in specific ways).

In the realm of the selection gestures, the thumb's opposition against the other fingers is present through the different treatment it receives in interval freedom. The maximum distance between thumb and index finger is the largest and makes the thumb a strategic element for the transition between hand shapes. Following a table elaborated by Richard Parncutt et al. [31], and using an original metric system based on the work of Matteo Balliauw [1], Moraes arrives at a list of 48 hand shapes (Table 2) arranged in parsimonious order ([20], pp. 13-15). This sequence generates a graph that shows how the hand extends and contracts as the shapes evolve through the register (Figure 6).

Excitation gestures comprise the ways the hand can distribute its movement between fingers to produce partitions. Research has already built a large amount of information about this subject that future works will cover.

Gentil-Nunes' formalization of melodic spaces is another proposal that concerns extending performative partitioning to monophonic instruments [14]. This research derives from another PA field, Linear Partitioning, that deals with the relations between lines inside melodic structures. A paper establishes the base for assessing the distribution of partitions in the flute's linear space.

\section{Partitional Complexes in Portal do Sol, from Codex Troano}

A Partitional Complex is the set of all potential combinations that can express a partition in time. This set comprises the partition itself, its subpartitions (partial sets of parts), subsums (partial sums of the parts), and subsums of subpartitions. This structure also points to the instrumentation of 


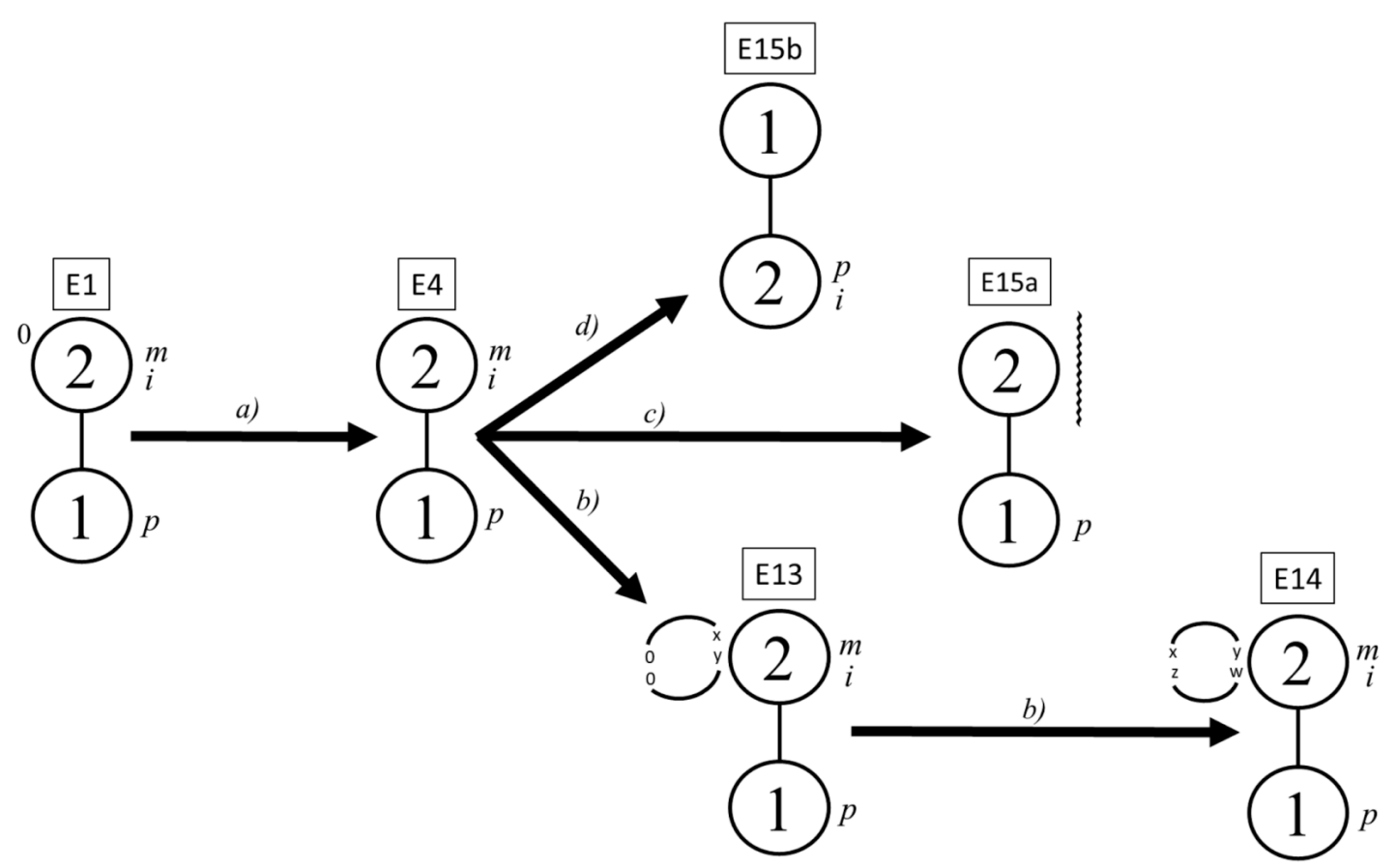

Figure 5: Etudes 1, 4, 13, 14, and 15 ([3]): net of parsimonious variations in the scope of GTPs formed by partition (1.2). a) assignment of linear motion to one part; b) left-hand procedures (ascending and descending slurs); c) right-hand procedures (FPA); d) inversion of register between parts ([35], p. 17).

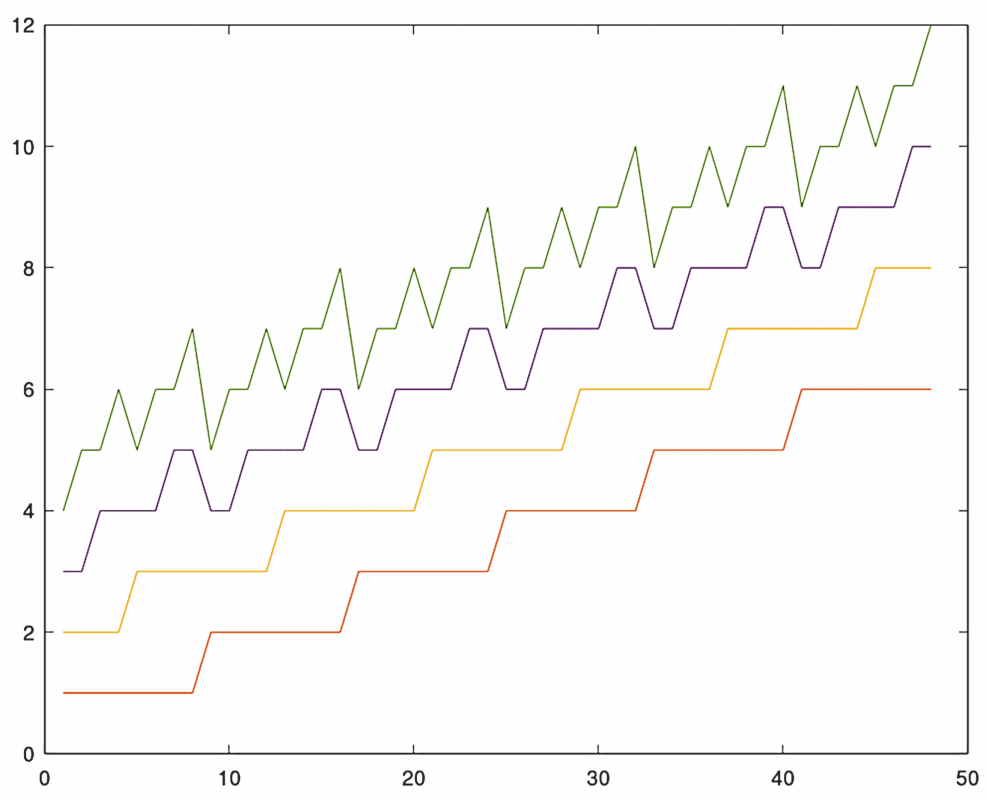

Figure 6: Progression of the 48 hand shapes (measured in balliauws) inside Parncutt's ergonomic comfort zone [20]. 
Table 2: List of all hand shapes (measured in balliauws) inside Parncutt's ergonomic comfort zone [20].

\begin{tabular}{|c|c|c|c|c|c|}
\hline $\mathbf{F}_{1}$ & 0 & 1 & 2 & 3 & 4 \\
\hline $\mathbf{F}_{2}$ & 0 & 1 & 2 & 3 & 5 \\
\hline $\mathbf{F}_{3}$ & O & 1 & 2 & 4 & 5 \\
\hline $\mathbf{F}_{4}$ & 0 & 1 & 2 & 4 & 6 \\
\hline $\mathbf{F}_{5}$ & 0 & 1 & 3 & 4 & 5 \\
\hline$F_{6}$ & 0 & 1 & 3 & 4 & 6 \\
\hline $\mathbf{F}_{7}$ & 0 & 1 & 3 & 5 & 6 \\
\hline $\mathbf{F}_{8}$ & 0 & 1 & 3 & 5 & 7 \\
\hline $\mathbf{F}_{9}$ & 0 & 2 & 3 & 5 & 5 \\
\hline $\mathbf{F}_{10}$ & O & 2 & 3 & 5 & 6 \\
\hline $\mathbf{F}_{11}$ & 0 & 2 & 3 & 5 & 6 \\
\hline$F_{12}$ & 0 & 2 & 3 & 5 & 7 \\
\hline $\mathbf{F}_{13}$ & 0 & 2 & 4 & 5 & 6 \\
\hline$F_{14}$ & 0 & 2 & 4 & 5 & 7 \\
\hline $\mathbf{F}_{15}$ & 0 & 2 & 4 & 6 & 7 \\
\hline$F_{16}$ & 0 & 2 & 4 & 6 & 8 \\
\hline
\end{tabular}

\begin{tabular}{|c|c|c|c|c|c|}
\hline $\mathbf{F}_{17}$ & 0 & 3 & 4 & 6 & 6 \\
\hline $\mathbf{F}_{\mathbf{1 8}}$ & 0 & 3 & 4 & 6 & 7 \\
\hline $\mathbf{F}_{19}$ & 0 & 3 & 4 & 6 & 7 \\
\hline $\mathbf{F}_{20}$ & 0 & 3 & 4 & 6 & 8 \\
\hline $\mathbf{F}_{21}$ & $\mathrm{O}$ & 3 & 5 & 6 & 7 \\
\hline $\mathbf{F}_{22}$ & 0 & 3 & 5 & 6 & 8 \\
\hline $\mathbf{F}_{23}$ & 0 & 3 & 5 & 7 & 8 \\
\hline $\mathbf{F}_{24}$ & 0 & 3 & 5 & 7 & 9 \\
\hline $\mathbf{F}_{25}$ & 0 & 4 & 5 & 6 & 7 \\
\hline $\mathbf{F}_{26}$ & 0 & 4 & 5 & 0 & 8 \\
\hline $\mathbf{F}_{27}$ & $\mathrm{O}$ & 4 & 5 & 7 & 8 \\
\hline$F_{28}$ & 0 & 4 & 5 & 7 & 9 \\
\hline $\mathbf{F}_{29}$ & 0 & 4 & 6 & 7 & 8 \\
\hline $\mathbf{F}_{30}$ & 0 & 4 & & 7 & 9 \\
\hline $\mathbf{F}_{31}$ & $\mathrm{O}$ & 4 & 6 & 8 & 9 \\
\hline $\mathbf{F}_{3}$ & 0 & 4 & 0 & 0 & 10 \\
\hline
\end{tabular}

\begin{tabular}{|l|l|l|l|l|l|}
\hline $\mathbf{F}_{33}$ & 0 & 5 & 6 & 7 & 8 \\
\hline $\mathbf{F}_{34}$ & 0 & 5 & 6 & 7 & 9 \\
\hline $\mathbf{F}_{35}$ & 0 & 5 & 6 & 8 & 9 \\
\hline $\mathbf{F}_{\mathbf{3 6}}$ & 0 & 5 & 6 & 8 & 10 \\
\hline $\mathbf{F}_{\mathbf{3 7}}$ & 0 & 5 & 7 & 8 & 9 \\
\hline $\mathbf{F}_{\mathbf{3 8}}$ & 0 & 5 & 7 & 8 & 10 \\
\hline $\mathbf{F}_{\mathbf{3 9}}$ & 0 & 5 & 7 & 9 & 10 \\
\hline $\mathbf{F}_{40}$ & 0 & 5 & 7 & 9 & $\mathbf{1 1}$ \\
\hline $\mathbf{F}_{41}$ & 0 & 6 & 7 & 8 & 9 \\
\hline $\mathbf{F}_{42}$ & 0 & 6 & 7 & 8 & 10 \\
\hline $\mathbf{F}_{43}$ & 0 & 6 & 7 & 9 & 10 \\
\hline $\mathbf{F}_{44}$ & 0 & 6 & 7 & 9 & 11 \\
\hline $\mathbf{F}_{45}$ & 0 & 6 & 8 & 9 & 10 \\
\hline $\mathbf{F}_{46}$ & 0 & 6 & 8 & 9 & $\mathbf{1 1}$ \\
\hline $\mathbf{F}_{47}$ & 0 & 6 & 8 & 10 & $\mathbf{1 1}$ \\
\hline $\mathbf{F}_{48}$ & 0 & 6 & 8 & 10 & 12 \\
\hline
\end{tabular}

the piece. We bring next an example of application in a composition for percussion ensemble.

André Codeço ([5], [6]) developed in 2014 a partitional analysis of Codex Troano, for percussion ensemble, by Roberto Victorio. Codeço shows that the first movement, Portal of Sun, is organized in a modular way, based on four textural gestures that appear throughout the piece in varied and recombined versions. The author defines the limits of each gesture based on its recurrences, which support his interpretation consistently. The four gestures presented in succession constitute the first syntagmatic unit of the piece (Figure 7).

As the piece has no bold melodic or harmonic features, the progressions between the simultaneous combinations of the instruments are among the leading forces in organizing the musical discourse.

Each gesture has a sequence of rhythmic partitions deduced from the vertical matchings between attack points and the duration of the individual notes: ${ }^{2}$

\footnotetext{
${ }^{2}$ The exponents indicate the part's multiplicity, and the dots only separate the parts that could mislead in some cases. For example, partition $\left(1^{3} 2\right)$ should read as (1.1.1.2). Partitions (1.3) and (13) can also be differentiated.
} 
a)

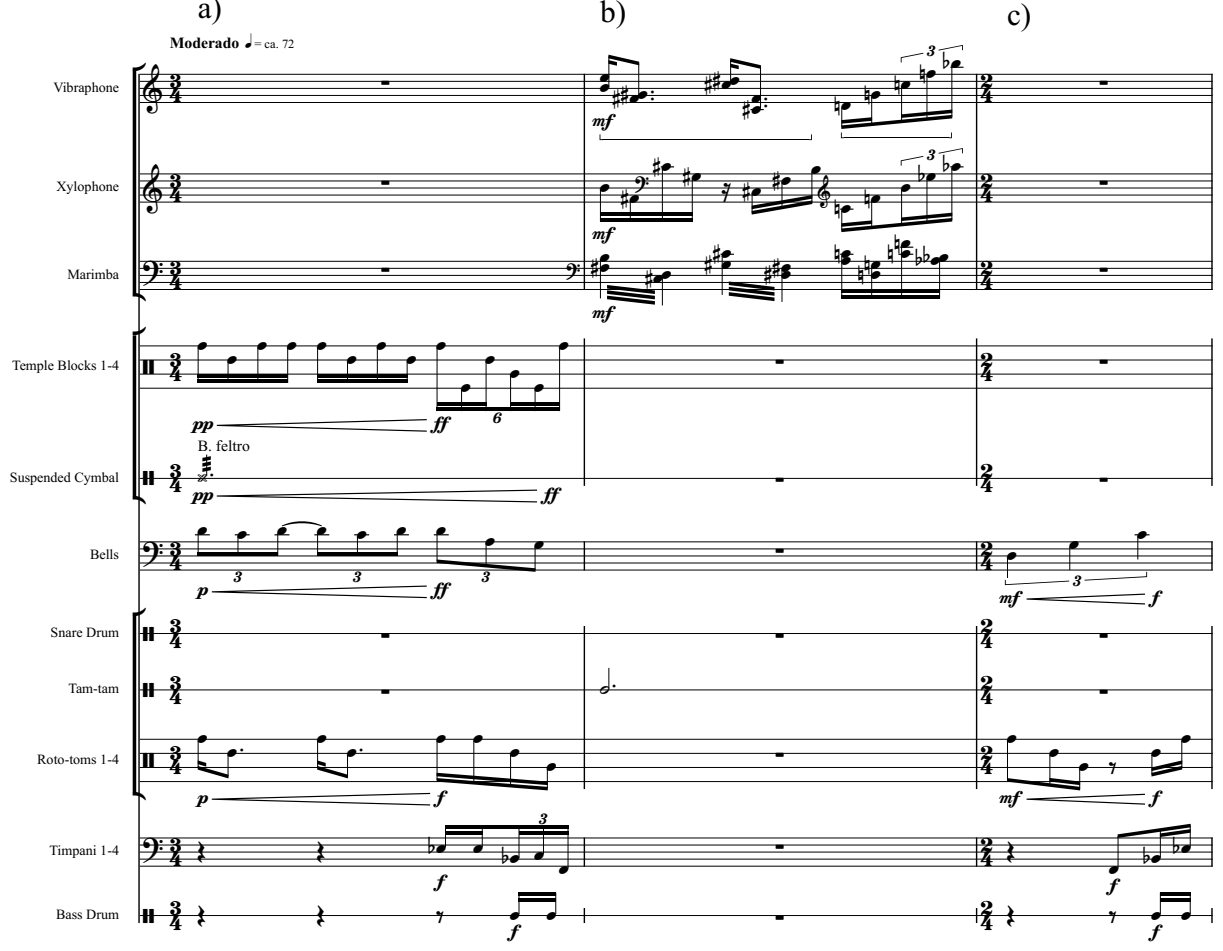

d)
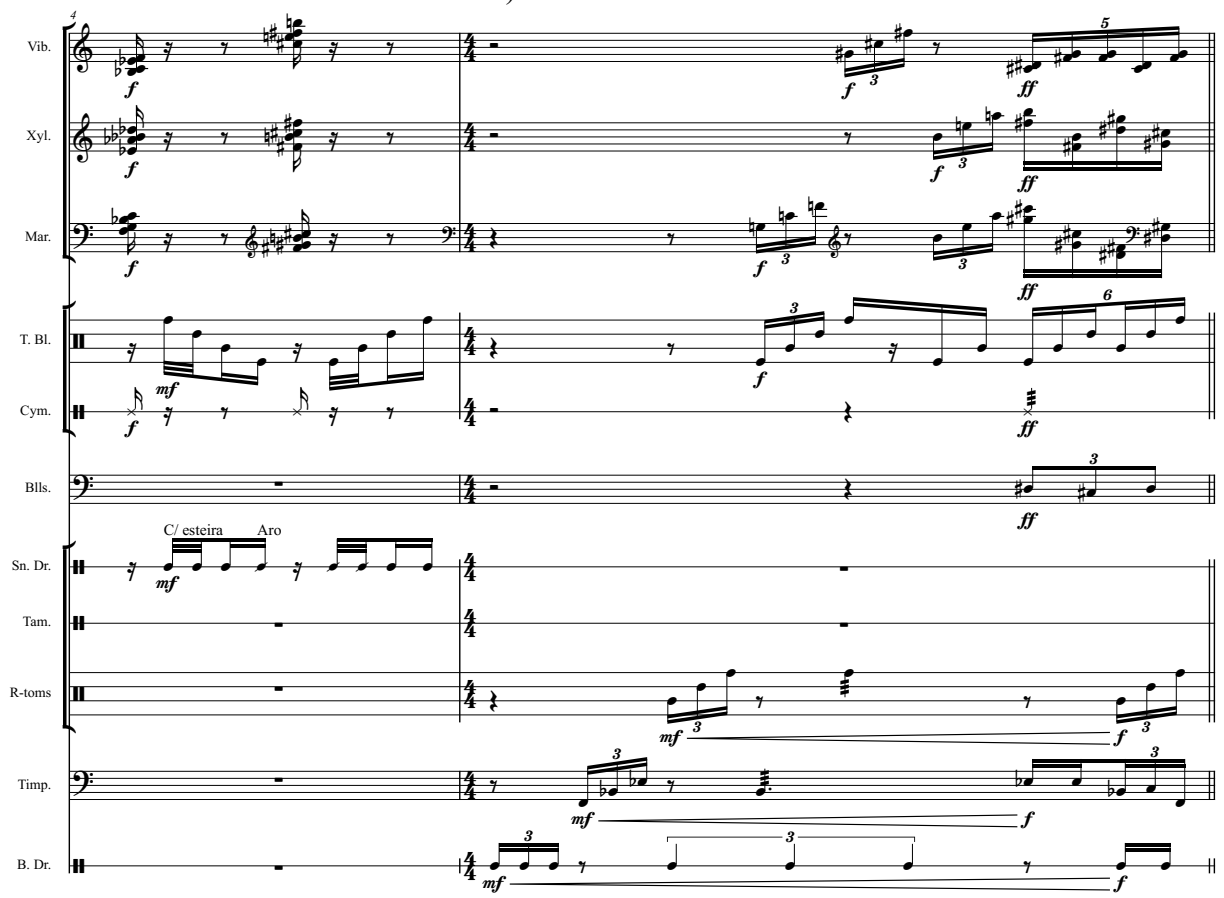

Figure 7: Codex Troano, I - Portal do Sol, by Roberto Victorio ([37], mm. 1-5): first occurrence of the four main textural gestures of the piece (namely, a, b, c, and d). 
1. Gesture $a-<\left(1^{2} 2\right)\left(1^{4}\right)\left(1^{3} 2\right)\left(1^{2} 2^{2}\right)>$

2. Gesture $b-<(1.2 .3)\left(1^{2} 2^{2}\right)\left(1.2^{2}\right)\left(1^{2} 2^{2}\right)(1.4)\left(1.2^{2}\right)>$

3. Gesture $c-<\left(1^{2}\right)(1.3)(13)(2)>$

4. Gesture $d-<(1)\left(1^{2}\right)\left(1^{2} 2\right)\left(1^{5}\right)\left(1^{4} 2\right)\left(1^{3} 2.5\right)\left(1^{2} 2.3 .5\right)>$

As each partition have its agglomeration and dispersion indexes, ${ }^{3}$ the delineated curves form what we call bubbles, e.g., arcs of textural growth and decline. In this particular case, the gestures $a$ and $b$ share the same bubble; this occurs as the recurrences show independence of thematic treatment during the piece (see [5], p. 31).

We visualize these arcs in the indexogram of the excerpt. Here we read the dispersion (delineated by the superior distance from the middle axis) and agglomeration curve (read by the inferior distance from the middle) both against the timeline of the excerpt, expressed by time points or beats (Figure 8 ).

Gestures $a$ and $b$ have more stable curves, while gesture $c$ and $d$ have extreme focal points in opposite directions. Gesture $c$ has two similar agglomeration peaks near time point 8 representing the more massive blocks of the excerpt (in this case, 13 instruments playing conjointly). On the other hand, gesture $d$ has a growing curve towards the maximum peak of dispersion (top level of polyphony or diversity of rhythmic profiles) near time point 14 . These two complementary peaks seem to balance each other and give a dramatic intensity for the first expository unit's closure, in contrast with the first two gestures, which seem to perform an accrual role. Considering the median line between the dispersion and agglomeration curves, one can then describe the textural profile's overall contour as $<1203>$. There are many other methods for extracting such patterns, which can be a methodology on its own. ${ }^{4}$

Partitional complexes can be visualized here as the result of the overall interaction between partitions inside a delimited section. The idea is that a textural configuration is not an atomic event. Instead, it is a construction, put into play by the gradual presentation of its constituent parts through the flow of time ([16], [21], [22]).

In Figure 8 we present partitional complexes above each associated gesture. They are, respectively, $\left(1^{4} 2^{2}\right),\left(1^{3} 2^{2}\right),\left(1^{2} 3.8\right)$, and $\left(1^{5} 2.5\right)$. The evaluation of each part as a subpartition, a subsum, or a combination of both leads to the referential partition. The last represents the overall textural mode of the gesture. This process can recur, forming a nested structure, organized in levels, like a schenkerian reduction, but departing from the score and pointing to the instrumentation. Instead of a centripetal movement, leading to the deep structure, the evaluation of partitional complexes points to the outermost surface, located in the external world (instrumentation, performativity, body).

\footnotetext{
${ }^{3}$ The agglomeration and dispersion indexes are the simple counts of the number of collaboration or contraposition binary relations between textural configuration elements (here, individual notes). In the case of rhythmic partitioning, collaboration means the convergence of attack point and duration and contraposition the mismatch between these two parameters ([13], pp. 33-57)

${ }^{4}$ Daniel Moreira developed this type of evaluation of texture by contour with great detail in [21].
} 


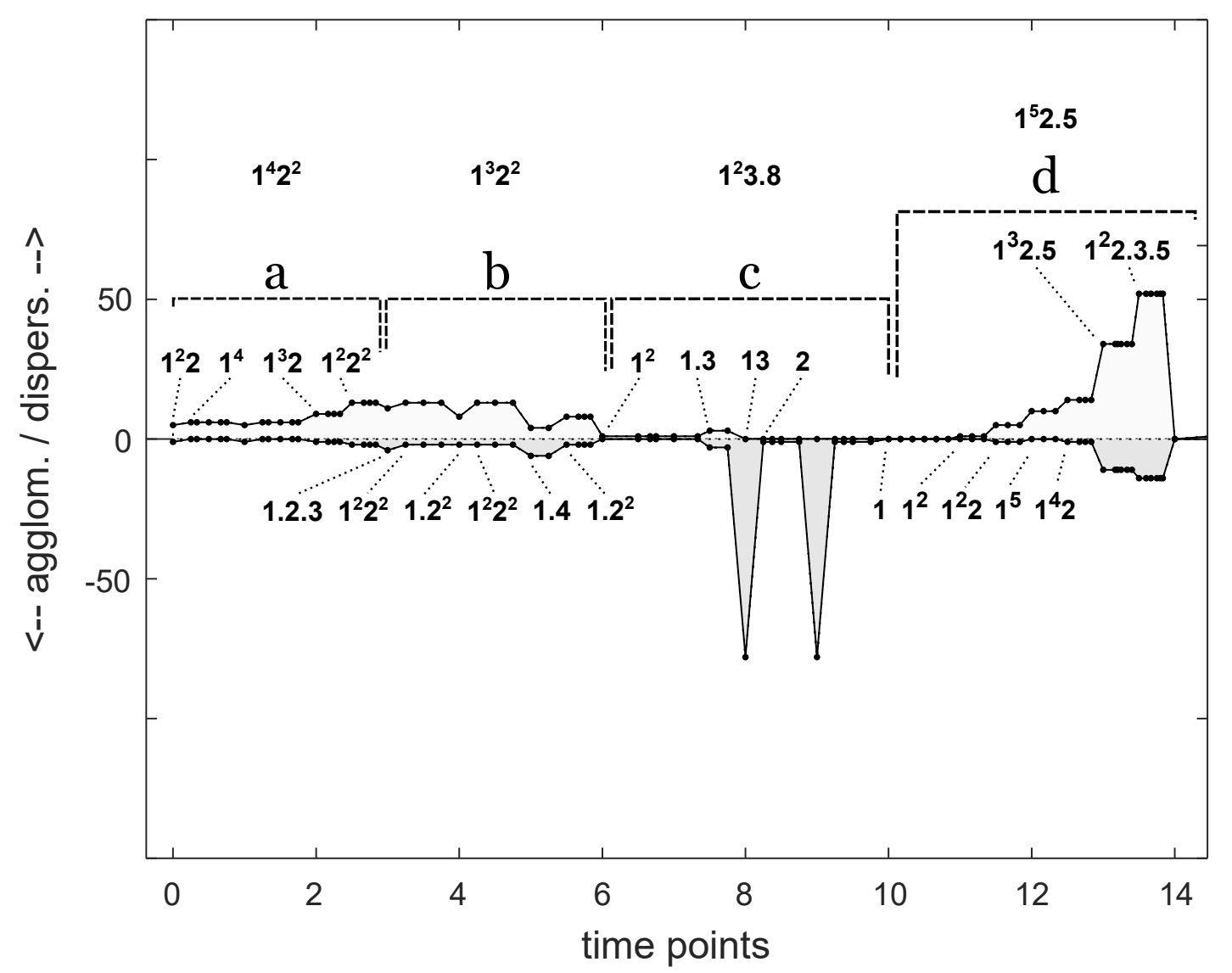

Figure 8: Codex Troano, I - Portal do Sol, by Roberto Victorio ([37], mm. 1-5): indexogram showing the four main textural gestures of the piece (namely, a, b, c, and $\mathrm{d}$ ) and associated partitions. We indicate referential partitions above the the delimitation of the gestures. Graphic produced by Parsemat $\AA$ [11], adapted from [5].

In this sense, the relations between the parts' distribution in partitions and complexes can give us some insights. For instance, in the gestures $a, b$, and $d$, there are some instruments that play a single role continuously, apparently promoting a function of stabilization and continuity. In gesture $a$, the cymbal and bells perform this role; in gesture $b$, this is performed by the tam-tam and marimba; and in gesture $d$, bass drum and timpani start this feature, and roto-toms and temple-blocks conclude it (Figure 9). Gesture $c$ then stands out as the prominent location of contrast in the section, with an actual rupture between partitions (1.3), (13) and (2), the last pair with no instrumental intersection at all (full contraposition).

On the other side, the remaining instruments are responsible for the most noticeable textural changes. The interplay between temple-blocks, roto-toms, timpani, and bass drums dominate gesture $a$. In gesture $b$, the shift in instrumentation to mallets is remarkable: xylophone and vibraphone articulate the progression. In gesture $d$, the textural game consists of a pyramidal structure - additive process and further agglomeration forming blocks.

Mallets, in this case, contribute to individual parts (1), (2), and (4). These parts happen to be the natural mode of the performativity of these instruments, as there are two arms, each with two mallets. Part (1) occurs with the alternation of the arms, striking one note at a time, eventually 
a)
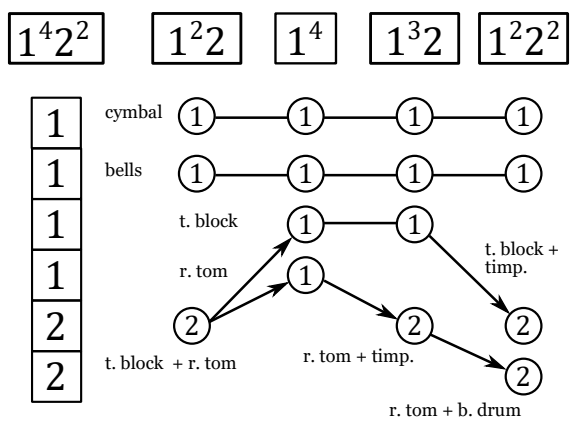

b)

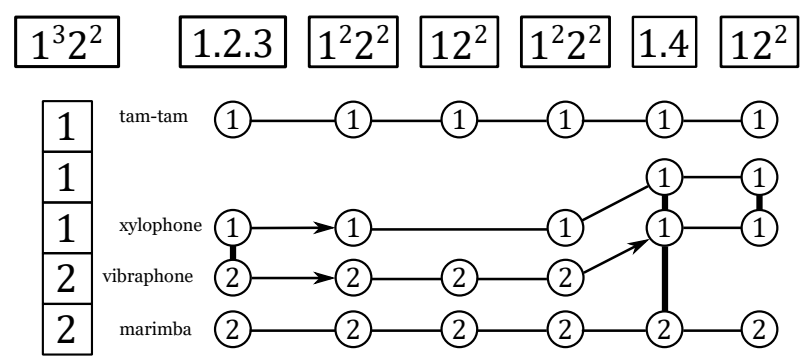

c)

d)

$1^{2} 3.8 \quad 1^{2} 1.313 \quad 2$

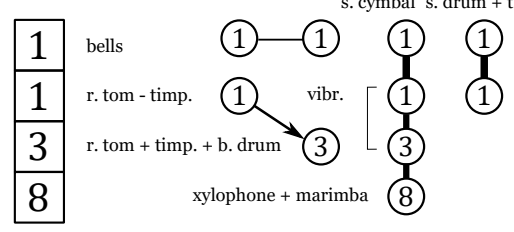

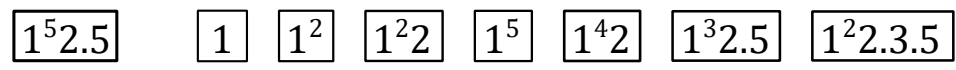
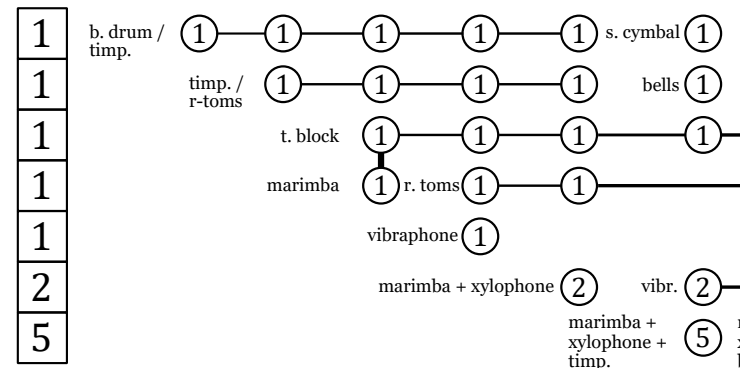

(1) (1) (1) bells (1)

(1)

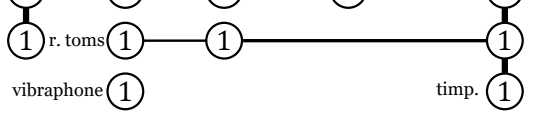

marimba + xylophone (2) vibr. (2) (2)

$\begin{aligned} & \text { marimba }+ \\ & \text { xylophone + (5) } \\ & \text { timp. }\end{aligned}$
$\begin{aligned} & \text { marimba +ophone + (5) } \\ & \text { b. drum }\end{aligned}$

Figure 9: Codex Troano, I - Portal do Sol, by Roberto Victorio ([37], mm. 1-5): partitions and instrumentation of the four main textural gestures of the piece (namely, a, b, c, and $\mathrm{d}$ ). The first column shows the partitional complex of each gesture. The remaining ones are the partitions and indicate how the parts and instrumentation fit into the referential partition. Arrows indicate the changing of an instrument from one part to another. Vertical bars mean subsums. The bracket in gesture c shows how we understand the part [4] as a subsum in one of the mallet percussion instruments (in this case, the vibraphone). Original conception of the present author. 


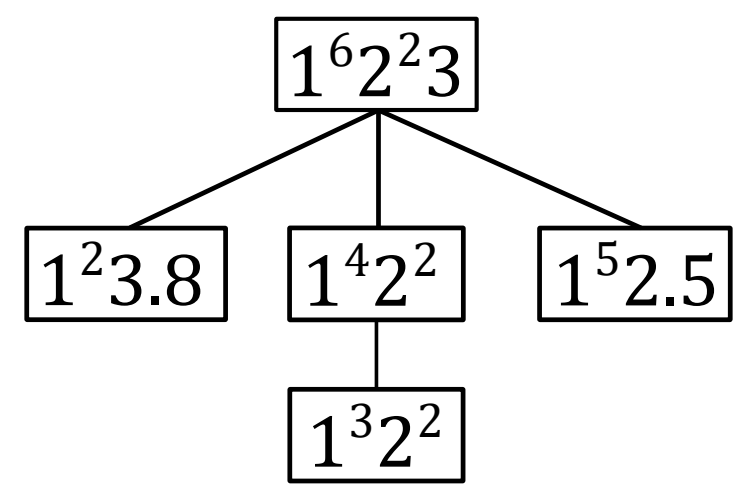

Figure 10: Codex Troano, I - Portal do Sol, by Roberto Victorio ([37], mm. 1-5): global partitional. Original conception of the present author.

articulating two successive notes with the same hand but another mallet. Part (2) implies a more obligatory alternation for a more fluid result, and mode (4) necessarily involves the two arms. Mallets can play three-note chords, but it is a more rare situation, as it implies in a slightly more unbalanced proposal.

All other eight instruments articulate only mode (1). Some of them have alternate use and can be played as a unitary instrument with variable timbre (for instance, the suspended cymbal and tam-tam could be played by one musician as a kit; the same observation for roto-toms and snare drum). This arrangement leads to the constitution of six unitary parts.

Part (3) in gesture $c$ is a subsum of three unitary instruments (roto-tom, timpani and bass drum), as part (5) in gesture $d$ is the subsum of two parts (2) and a single part (1) - marimba, xylophone and timpani. Finally, part (8) is the most massive and constitutes a compound unity, as it is the only part where the mallets act as a single massive instrument, each articulating a part (4) (in turn, this parts (4) are subsums of parts (2) and (1), as stated before). Here we are considering the two already existent parts, (1) and (3), subsumed to compose one of the parts (4) - we attribute it to vibraphone just for clarity, as it is only a conceptual option.

The next step is evaluating the interactions between the partitional complexes of each gesture to arrive at the partitional complex of the entire section. As we consider each partition as a set of subpartitions, subsums, or combinations of both, we conclude that the referential partition is $\left(1^{6} 2^{2} .3\right)$ (Figure 10).

\section{Spatial PARtitioning AND CONClusions}

As an epilogue, we bring some preliminary observations about Spatial Partitioning, an application foreseen in previous works. As the analyst can choose a partitioning criterion, and the research directs towards contexts linked to the surface, applying partitioning to space became a natural outcome.

Fleeing from a platonic or phenomenological approach, we intend to start the work from the study of the historical use of spatial dispositions in concert music.

Concert music develops under the project of Italian Renaissance theater, which is based on the experience of perspective, that is, the most important dimensions in the pictorial field, which are width and depth ( $x$ and $z$ dimensions). We in fact cannot see the development of a truly vertical spatial sense of sound on the Italian stage ( $y$ dimension) as it was abandoned after Monteverdi 


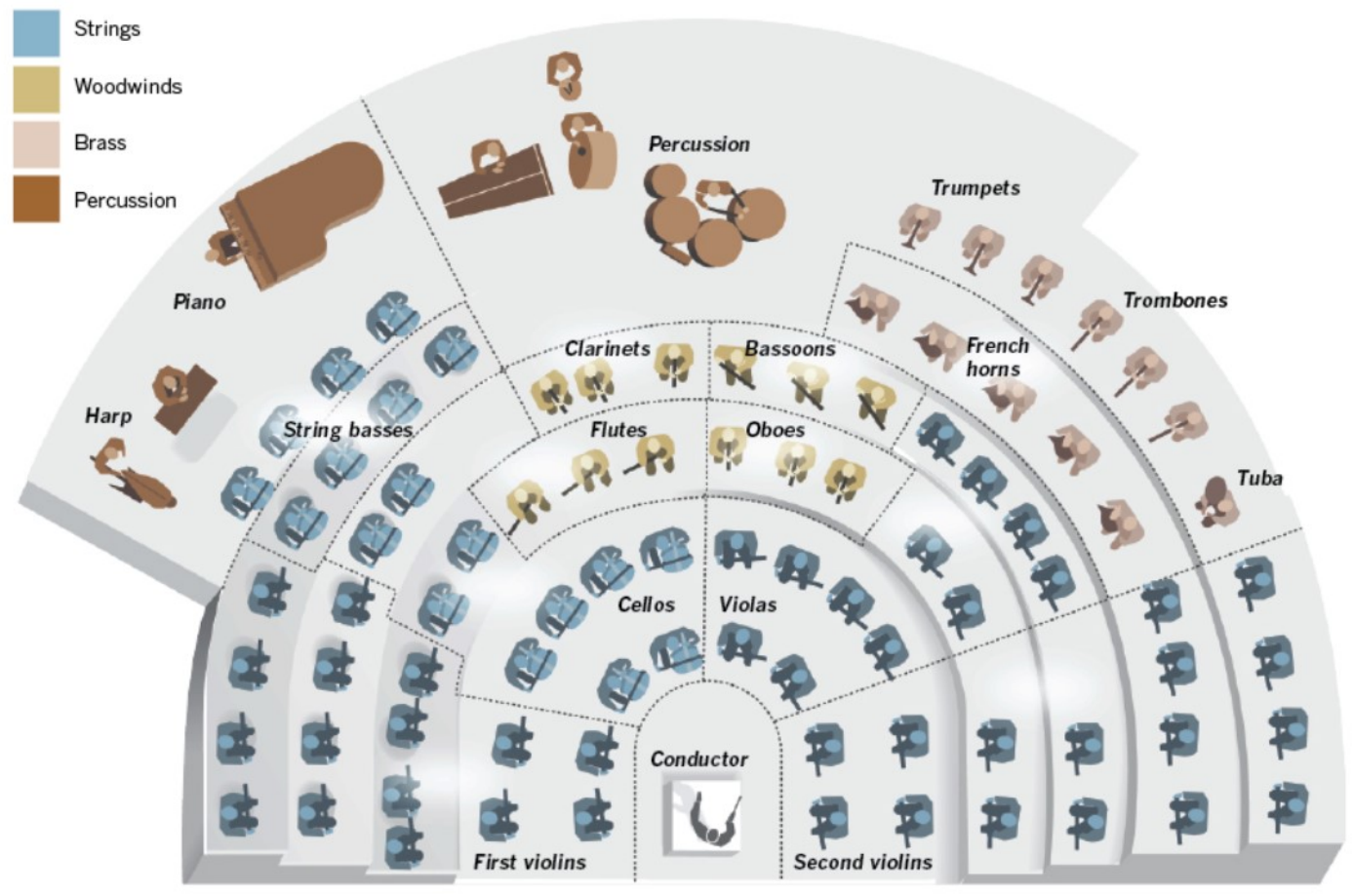

Figure 11: Concentric spatial layout of the classical orchestra ([32]).

and Gabrielli's experiences of more immersive spatialization within churches. Even today, the arrangement of speakers always favors the horizontal arrangement, with important but rare exceptions like multichannel speaker arrays.

Width is translated generically today by the term panoramic, with right and left channels being the basis of a stereo listening. This listening has as reference to the binaural nature of our auditory perception.

The element of depth translates in two ways, one more concrete and another, more virtual, related to the technology of music recording.

On stage, instruments that carry more individual and foreground expressions are positioned, usually, in the proscenium (i.e., as close as possible to the audience). This is the place of the soloist in concert with orchestra, or the singer in the opera arias. This position allows the sound content of the source to prevail over its reverberation - a drier sound.

Otherwise, instruments that perform background functions tend to be positioned at the rear of the stage. For example, the orchestra's choir or percussion instruments, which have a less tonic sound, as a rule, and additionally are wetter.

This dimension is translated into music technology as reverberation. Of course, there are other elements involved, such as the spectral profile, whose internal relationships change as the spatial recession is applied. Using too little reverb leads to a virtual approximation of the source, while a higher level of reverb tends to cause the sensation of withdrawal.

The orchestra organization seems to replicate this structure, with the orchestral sections being organized by concentric circles, which are successively occupied by strings, woods, brass and percussion. There are also some concerns about the relative volume of instruments - louder 
instruments that are allocated in the background, where they can thus balance with more delicate instruments in the proscenium (Figure 11).

Thus, it is hoped that an analysis can be developed from the placement of instruments on the stage, where the partitions would take place in two dimensions - in the groups that are established by the distribution of musical achievements in the horizontal range, in terms of the panoramic; and by the relative depth of the instruments on stage, both in terms of physical position and the driest or wettest level in the source/reverberation relationship.

Spatial partitioning can arise as a complement to the research about textural configurations. The study of the grounding of texture on the physical world is just beginning, and there is much room for expansions and new proposals. We hope that this research can fulfill a progressive departure from the domain of traditional music theory (mainly harmony and form) to an encounter (from a point of view derived from the linguistic-pragmatic turn) with music's social foundations. Along with all the proposals described in this article, a path is emerging to meet with other musical traditions where the body and physicality are already part of the daily musical experience.

\section{REFERENCES}

[1] Balliauw, M. (2014) A Variable Neighbourhood Search Algorithm to Generate Piano Fingerings for Polyphonic Sheet Music. Thesis (Masters in Applied Economic Sciences), University of Antwerp.

[2] Boyle, A. (2018) Formation and Process in Repetitive Post-Tonal Music. Dissertation (Ph.D. in Music), University of British Columbia. Available in: https://open.library.ubc.ca/ collections/ubctheses/24/items/1.0371135, accessed on 26/12/2020.

[3] Brouwer, L. (1972) 20 Estudios Sencillos. Acoustic Guitar. Score. Paris: Max Eschig.

[4] Cadoz, C. (1988) Instrumental Gesture and Musical Composition. In: ICMC — International Computer Music Conference, 14., Proceedings... Cologne, Germany, pp. 1-12.

[5] Codeço, A. (2014) Gesto textural e planejamento composicional. Thesis (Masters in Music), Federal University of Rio de Janeiro. Available in: https://drive.google.com/file/d/ 11pXQ086buxf00LuZGJFwrDg Jd09PAD0D/view?usp=sharing, accessed on 24/12/2020.

[6] Codeço, A. (2015) Movimento de derivação gestual textural no I movimento de Codex Troano. In: Congresso da ANPPOM, 25. Proceedings... Vitória: Federal UNiversity of Espírito Santo. Available in: https://anppom.com.br/congressos/index.php/25anppom/ Vitoria2015/paper/view/3810, accessed on 16/06/2019.

[7] Erickson, R (1975) Sound Structure in Music. Berkeley: University of California.

[8] Fink, R. (1999) Going Flat: Post-Hierarchical Music Theory and the Musical Surface. In: Cook, N.; Everist, M. (eds.) Rethinking Music. Oxford: Oxford University. pp. 102--137.

[9] Friedmann, M. (1985) A Methodology of the Discussion of Contour: Its Application to Schoenberg's Music. Journal of Musical Theory, 29/2, pp. 223-248.

[10] Gentil-Nunes, P.; Carvalho, A. (2003) Densidade e linearidade na configuração de texturas musicais. In: Colóquio de Pesquisa do Programa de Pós-Graduação em Música da UFRJ, 4. Proceedings..., Federal University of Rio de Janeiro. Available in: https://www .academia. edu/4393959, accessed on 16/06/2019. 
[11] Gentil-Nunes, P. (2004) PARSEMAT - Parseme Toolbox Software Package. Rio de Janeiro: Pauxy Gentil-Nunes. Available in: https://pauxy .net/parsemat-2/, accessed on 25/12/2020.

[12] Gentil-Nunes, P. (2005) Partições e música: uma pequena resenha. In: Congresso da ANPPOM. Proceedings... Rio de Janeiro: Federal University of Rio de Janeiro.

[13] Gentil-Nunes, P. (2009) Análise Particional: uma mediação entre composição e a Teoria das Partições. Dissertation (Ph.D. in Music). Universidade Federal do Estado do Rio de Janeiro. Available in: https://www. academia.edu/4405471, accessed on 16/06/2019

[14] Gentil-Nunes, P. (2016) Formalização do espaço textural melódico em instrumentos monofônicos. In: Congresso da ANPPOM, 26. Proceedings... Belo Horizonte: State University of Minas Gerais. Available in: https://www. anppom.com.br/congressos/index.php/26anppom/ bh2016/paper/view/4332, accessed on 26/12/2020.

[15] Gentil-Nunes, P. (2017) Partitiogram, Mnet, Vnet, and Tnet: Embedded Abstractions Inside Compositional Games. In: Pareyon G.; Pina-Romero S.; Agustín-Aquino O.; Lluis-Puebla E. (eds) The Musical-Mathematical Mind: Patterns and Transformations. Cham: Springer, pp. 111118. Available in: https://link. springer.com/chapter/10.1007/978-3-319-47337-6_12, accessed on $05 / 20 / 2019$.

[16] Gentil-Nunes, P. (2018) Superfície e estrutura em aplicações da Análise Particional. Rio de Janeiro: PPGM-UFRJ. Available in: https://ppgm.musica.ufrj.br/ superficie-e-estrutura-em-aplicacoes-da-analise-particional-2018/, accessed on $26 / 12 / 2020$.

[17] Gentil-Nunes, P. (2018). Nesting and Intersections Between Partitional Complexes. MusMat: Brazilian Journal of Music and Mathematics, 2/1, pp. 93-108. Available in: https://musmat. org/wp-content/uploads/2018/06/09-Pauxy ·pdf, accessed on 05/20/2019.

[18] Levy, J. (1982) Texture as a Sign in Classic and Early Romantic Music. Journal of the American Musicological Society, 35/3, pp. 482--531. Available in: https://online.ucpress.edu/jams/article-abstract/35/3/482/49237/ Texture-as-a-Sign-in-Classic-and-Early-Romantic?redirectedFrom=PDF, accessed on $26 / 12 / 2020$.

[19] Marvin, E.; Laprade, P. (1987) Relating Musical Contours: Extensions of a Theory for Contour. Journal of Music Theory, 31/2, pp. 225-67.

[20] Moraes, P. (2020, in press) O corpo como fator de modelagem da textura pianística. In: Gentil-Nunes (org.). Teoria musical no Brasil: diálogos intercontinentais. Série Congressos da TeMA, 4. Rio de Janeiro: Federal University of Rio de Janeiro.

[21] Moreira, D. (2019) Composing with Textures: A Proposal of the Formalization of Textural Spaces. MusMat: Brazilian Journal of Music and Mathematics, 3/1, pp. 19-48. Available in: https: //musmat.org/wp-content/uploads/2019/07/07-Moreira.pdf, accessed on 28/12/2020.

[22] Moreira, D. (2019) Textural Design: A Compositional Theory for the Organization of Musical Texture. Dissertation (Ph.D. in Music). Rio de Janeiro: Federal University of Rio de Janeiro.

[23] Moreira, D. (2017) Textural Contour: A Proposal for Textural Hierarchy Through the Ranking of Partitions lexset. In: Pareyon G.; Pina-Romero S.; Agustín-Aquino O.; Lluis-Puebla E. (eds) The Musical-Mathematical Mind: Patterns and Transformations. Cham: Springer, pp. 199-206. 
[24] Moreira, D. (2016) Contornos musicais e textura: perspectivas para análise e composição. In: Brazilian Symposium of Graduate Studies in Music (SIMPOM), 4. Proceedings.... Rio de Janeiro: Universidade Federal do Estado do Rio de Janeiro, pp. 99-109.

[25] Moreira, D. (2016) Contornos particionais: aplicações metodológicas na Introdução da Sagração da Primavera de Igor Stravinsky. In: Colóquio de Pesquisa do Programa de Pós-Graduação em Música da UFRJ, 12.Proceedings... Rio de Janeiro: Federal University of Rio de Janeiro. Available in: https://ppgmufrj.files.wordpress.com/2016/06/ 04-contornos-particionais.pdf, accessed on 05/20/2019.

[26] Moreira, D. (2015) Perspectivas para a análise textural a partir da mediação entre a Teoria dos Contornos e a Análise Particional Thesis (Masters in Music). Rio de Janeiro: Federal University of Rio de Janeiro.

[27] Moreira, D. (2014) Contour Analyzer: Computational tool for the analysis of musical contours. Art Music Review, 27, p. 13.

[28] Moreira, D.; Gentil-Nunes, P. (2015). Ornamental Functions in Textural Domain from the Proposal for a Textural Contour. In: Congresso da ANPPOM, 25. Proceedings... Vitória:Federal University of Rio de Janeiro.Available in: https://anppom.com.br/congressos/index.php/ 25anppom/Vitoria2015/paper/view/3440, accessed on 05/20/2019.

[29] Morris, R. (1987) Composition with Pitch-classes: A Theory of Compositional Design. New Haven: Yale University Press.

[30] Morris, R. (1993) New directions in the Theory and Analysis of Musical Contour. Music Theory Spectrum, 15, pp. 205-28.

[31] Parncutt, R.; Sloboda, J.; Clarke E.; Raekallio, M.; Desain, P. (1997) An Ergonomic Model of Keyboard Fingering for Melodic Fragments. Music Perception: An Interdisciplinary Journal, 14/4, pp. 341-382.

[32] Pesce, A. (2013) Disney Hall: Inside and Out. Los Angeles Times: Data Desk. Published in Sept. 20, 2013. Available in https://graphics.latimes.com/ storyboard-disney-hall-inside-and-out/, accessed in 20/10/2019.

[33] Ramos, B. (2017) Análise de textura violonística: teoria e aplicação. Thesis (Masters in Music). Rio de Janeiro: Federal University of Rio de Janeiro.

[34] Gentil-Nunes, P.; Ramos, B. (2016) Complexos Particionais. In: Congresso Nacional de Música e Matemática, 2. Proceedings... Rio de Janeiro: Federal University of Rio de Janeiro. Available in: https://musmat.org/en/congresso/anais-2016/, accessed on 27/12/2020.

[35] Ramos, B; Gentil-Nunes, P. (2020) Parsimonious Relations Between Guitar Textural Proposals. Vortex, 8/3, pp. 1-21. Available in: http://vortex.unespar.edu.br/ramos_gentilenunes_ v8_n3.pdf, accessed on 26/12/2020.

[36] Ramos, B; Gentil-Nunes, P. (2014) A Análise particional e o idiomatismo textural do violão. In: Colóquio de Pesquisa do Programa de Pós-Graduação em Música da UFRJ, 13. Proceedings... Rio de Janeiro: Federal University of Rio de Janeiro, pp. 15-23. Available in: https://ppgmufrj.files.wordpress.com/2016/06/ 02-ramos-gentil-nunes-a-anc3a1lise-particional-e-o-idiomatismo.pdf, accessed on $26 / 12 / 2020$. 
Journal MusMat • December $2020 \bullet$ Vol. 4, No. 2

[37] Victorio, R. (1987) Codex Troano. Percussion Ensemble. Score (manuscript). Available in: http://www.robertovictorio.com.br/index.php/partituras/partitura-percurssao/ codex-troano, accessed on 24/12/2020. 